\title{
Electroporation Can Efficiently Transfect hESC-Derived Mesenchymal Stem Cells without Inducing Differentiation
}

\author{
Anthony J. Sprangers ${ }^{\dagger}$, Brian Freeman ${ }^{\dagger}$ and Brenda M. Ogle ${ }^{*}, \S$ \\ Departments of Biomedical Engineering ${ }^{\dagger}$, the Laboratory for Optical and Computational Instrumentation ", and the \\ Material Sciences Program ${ }^{\S}$, University of Wisconsin at Madison, Madison, Wisconsin 53706, USA
}

\begin{abstract}
Electroporation is a common method of gene transfer that has recently been used to efficiently transfect mesenchymal stem (stromal) cells (MSCs); however, the electrical stimulus has the potential to alter cell state. This study examines possible negative effects of electroporation of human embryonic stem cell (hESC)-derived MSCs including, loss of potency or induction of differentiation. Immunofluorescence and PCR were used to quantify protein and RNA expression of CD73 (an MSC marker) and markers of mature mesenchymal cell types following electroporation. The relative fraction of cells expressing CD73 protein was not altered in cells exposed to a $20 \mathrm{~ms}$ pulse at $1000 \mathrm{~V}$ or $1500 \mathrm{~V}$ compared to controls even after three passages, suggesting MSCs retain multipotency following electroporation. In addition, RNA expression of markers indicative of mature cells of bone, fat and cardiac muscle did not differ from unmanipulated controls soon after electroporation. Taken together, these results indicate electroporation under conditions favorable for MSC transfection does not significantly alter stem cell state.
\end{abstract}

Keywords: Electroporation, stem cells, mesenchymal stem cells, differentiation, transfection.

\section{INTRODUCTION}

Mesenchymal stem cells (MSCs) have become increasingly popular for tissue regeneration because of their ability to differentiate into many types of tissues while suppressing immune responses and promoting vasculogenesis [1-3]. Understanding the function and capabilities of these cells is partially dependant on the ability to genetically modify the cells and evaluate associated responses. Genetic modification is commonly performed via chemical transfection or viral infection. Chemical transfection of genetic material is achieved using polycationic polymers or liposomes. This method is inexpensive and easy to implement, however transfection efficiencies are very poor for stem cells, including MSCs, and inefficient integration into the genome makes the generation of stable transformants exceedingly difficult [4]. Viral infection is an effective means of gene transfer for mesenchymal stem cells, however vector constructs larger than $\sim 11 \mathrm{~kb}$ are poorly packaged and thus poorly transferred. In addition, the random nature of genomic integration of retroviral and lentiviral vectors can be cytopathic or cause unwanted modification and mutation of the cell genome [5].

Electroporation is an alternative strategy for gene transfer. Electroporation is performed by exposing cells to an electric field that surpasses the dielectric constant of the cell membrane [6-10]. Surpassing the transmembrane potential causes a destabilization of the cell membrane which results in concave pore formation within the membrane $[8,9]$.

*Address correspondence to this author at the University of WisconsinMadison, 2-114 Engineering Centers Building, 1550 Engineering Drive, Madison, WI 53706, USA; Tel: 608-265-8267; E-mail: ogle@wisc.edu
These pores can potentially form in either the lipid bilayer or protein channels [10]. Permeabilization of the membrane allows for flux of a DNA plasmid and/or other exogenous materials (e.g. proteins, ions, etc.) in to and out of the cell $[8$, 9]. Uncontrolled flux of material across the cell membrane can lead to disruption of cell homeostasis and, in some cases, cell death. However, electroporation can efficiently transfect primary cells, including MSCs $[4,5,11,12]$ and recent advances have improved cell throughput and so the ability to scale studies for large animal or human use.

Following electroporation, MSCs exposed to electrical stimulation have been shown to maintain the capacity to differentiate into chrondogenic, adipogenic, and osteogenic lineages $[5,11]$. Yet unclear however, is whether electroporation can initiate unintended differentiation. Others have shown that a non-invasive electric field $(2 \mathrm{~V} / \mathrm{cm})$, can increase the tendency of the membrane of MSCs to be deformed elastically with an applied force and as a consequence a phenotype resembling that of osteoblasts can be induced [13]. In addition, the application of an electric field can facilitate osteogenic differentiation in MSCs and alter $\mathrm{Ca}^{2+}$ dynamics [14]. Finally, when applied to embryonic stem cells, an electric field assists in cardiogenic differentiation [15].

This study was conducted to test whether electroporation per se, under conditions appropriate for gene transfection, can induce near-term differentiation of hESC-derived MSCs. To this end, markers for osteogenic (i.e. osteocalcin and osteopontin), cardiogenic (cardiac troponin-T), and adipogenic (PPAR $\gamma-2)$ cell types were evaluated following electroporation. In addition, the potential loss of multipotency of MSCs was evaluated by tracking CD73 protein expression following electroporation. 


\section{MATERIALS AND METHODOLOGY}

\section{MSC Culture}

Mesenchymal stem cells were derived from $\mathrm{H} 1$ human embryonic stem cells [16] and termed H1MSCs (kindly provided by P. Hematti, University of Wisconsin-Madison). H1MSCs were cultured using $\alpha$-MEM medium (Invitrogen, Carlsbad, CA) supplemented with $1 \%$ non essential amino acids (NEAA, GIBCO/Invitrogen) and 10\% fetal bovine serum (FBS) at $37^{\circ} \mathrm{C}$ in $5 \% \mathrm{CO}_{2}$. Cells were plated at $3.3 \mathrm{x}$ $10^{5}$ cells per $175 \mathrm{~cm}^{2}$ and harvested when $70 \%$ confluent. Medium was changed one day after plating and every 3 days thereafter. Cells were harvested via application of trypsin for approximately 5 minutes and pelleted using a centrifuge at $300 \mathrm{x} g$ for 5 minutes. Supernatant was removed and cells were resuspended in medium.

\section{Electroporation}

Electroporation was performed using the Neon Transfection System (Invitrogen). Cells were prepared per the manufacturer protocol. Electroporation was conducted with $2 \mu \mathrm{g}$ of DNA plasmid per $5.0 \times 10^{5}$ cells using $2.0 \times 10^{5}$ cells per transfection. Cells were transfected with a pMXGFP reporter plasmid [17] and plated in 6 well plates $(n=3$ separate experiments) with fresh medium. A control cellular fraction was plated at the same cell density without electroporation. Medium was changed 24 hours after electroporation. Initial optimization was conducted per the manufacturer protocol and ideal transfection was attained at a pulse magnitude and duration of $1500 \mathrm{~V}$ and $20 \mathrm{~ms}$ respectively (data not shown). To further refine the electroporation protocol, additional conditions were evaluated, with a single pulse applied in the range of $900-1700 \mathrm{~V}$ at $100 \mathrm{~V}$ increments for a duration of $20 \mathrm{~ms}$. Transfection efficiency was determined 48 hours after transfection using fluorescence microscopy and was calculated as a percent of $\mathrm{GFP}^{+}$cells relative to the total number of cells per field ( $\mathrm{n}>4$ fields per condition; fields were selected based on the presence of cell nuclei identified via DAPI staining). Cell counts were performed for all conditions and viability was calculated as a percentage of the total number of electroporated cells per well relative to the total number of cells per well in control cultures. A transfection score was calculated to determine the optimum pulse magnitude. The transfection score was defined as follows and is derived from the assumption that cell viability and transfection efficiency are of equal importance: (Viability * Efficiency)/20.

\section{CD73 Protein Expression}

To track CD73 expression, H1MSCs were electroporated at $0 \mathrm{~V}$ (control), $1000 \mathrm{~V}$, and $1500 \mathrm{~V}$, with a $20 \mathrm{~ms}$ pulse. Cells were electroporated and seeded at $1.4 \times 10^{5}$ and $1.8 \times$ $10^{5}$ cells per well $\left(9.6 \mathrm{~cm}^{2}\right)$ of a six-well plate for the $1000 \mathrm{~V}$ and $1500 \mathrm{~V}$ conditions, respectively. Control cells (not electroporated) were seeded at $5.0 \times 10^{5}$ cells per T175 (175 $\mathrm{cm}^{2}$ ). Cell concentrations at seeding were altered to account for differences in cell viability with different pulse magnitudes in an effort to produce similar plating densities following electroporation. Electroporation was conducted without the reporter plasmid to eliminate potential overlap of fluorescence emission between the GFP signal and the immuno- fluorescence signal corresponding to CD73 expression. Cells were cultured with standard medium changes and harvested when $70 \%$ confluent. For staining, cells were plated in 8 well chamber slides at $3.5 \times 10^{3}$ cells per chamber $\left(0.8 \mathrm{~cm}^{2}\right)$.

Immunofluorescence staining was performed as previously described [18] in the 8 well chamber slides when the cells reached $50 \%$ confluency. Slides were washed with $1 \mathrm{x}$ PBS and placed in $100 \%$ acetone (cooled to $4^{\circ} \mathrm{C}$ ) for 10 minutes. Slides were allowed to air dry for 10 minutes and placed in 1\% PFA for 2 minutes, and then washed with $1 \mathrm{x}$ PBS. A 1:25 dilution of the anti-CD73 antibody (Sc-14682, Santa Cruz Biotechnology, Santa Cruz, CA) with 3\% BSA (Fisher, Forest Lawn, NJ) was prepared and $50 \mu 1$ aliquots were place on each chamber and incubated overnight at $4^{\circ} \mathrm{C}$. Slides were washed with $1 \mathrm{x}$ PBS and $50 \mu$ aliquots of a 1:200 dilution of the secondary antibody (AF488 Donkey anti-Goat, Invitrogen, Carlsbad, CA) with a diluting buffer, prepared 9:1 of 5\% BSA and human pooled serum (CELLect, ICN Biomedical Inc, Aurora, OH), was placed atop the chambers. The secondary solution was allowed to incubate for 45 minutes at room temperature. Slides were washed with 1x PBS and mounted using DAPCO/DAPI (Sigma Aldrich) and a microscope cover slip. Imaging was conducted immediately after staining using a 10X objective with the IX2 Research Inverted System Microscope (Olympus, Center Valley, PA). Percentage of $\mathrm{CD}^{+} 3^{+}$cells was determined relative to the total cell number per field ( $\mathrm{n}$ $>4$ fields per condition; fields were selected based on the presence of cell nuclei identified via DAPI staining). CD73 expression was tracked for three cell passages.

\section{RNA Expression of Markers of Mature Mesenchymal Cell Types}

Cells were electroporated and subsequently seeded as described for CD73 analysis. Cells were cultured with regular medium changes for one passage and harvested when 70 $80 \%$ confluent. RNA was extracted (PerfectPure RNA Culture Cell kit, 5 PRIME, Gaithersburg, MA) per the manufacturer protocol and used for cDNA synthesis (ThermoScript, Invitrogen). PCR was performed with primers for $\beta$-actin, osteopontin, osteocalcin, cardiac troponin-T, and PPAR $\gamma-2$ (Table 1) and products were separated on an agarose gel. Band intensity corresponding to the gene of interest was determined using Quantity One (BioRad, Hercules, CA). Results are reported as the intensity of the marker band relative to the intensity of the $\beta$-actin band.

Table 1. RT-PCR Primers for Markers of Mature MSCs

\begin{tabular}{|c|c|c|}
\hline Lineage Marker & Forward & Reverse \\
\hline \hline$\beta$-Actin & $\begin{array}{c}\text { ATG TTT GAG ACC } \\
\text { TTC AAC }\end{array}$ & $\begin{array}{c}\text { CAC GTC ACA CTT } \\
\text { CAT GAT }\end{array}$ \\
\hline Osteocalcin & $\begin{array}{c}\text { ATG AGA GCC CTC } \\
\text { ACA CTC }\end{array}$ & $\begin{array}{c}\text { GCC GTA GAA GCG } \\
\text { CCG ATA }\end{array}$ \\
\hline Osteopontin & $\begin{array}{c}\text { CAT CTC AGA AGC } \\
\text { AGA ATC }\end{array}$ & $\begin{array}{c}\text { CCA TAA ACC ACA } \\
\text { CTA TCA }\end{array}$ \\
\hline Cardiac & AGG CGC TGA TTG & ATA GAT GCT CTG \\
Croponin-T & AGG CTC CAG \\
\hline PPAR $\gamma-2$ & $\begin{array}{c}\text { AAG ACC ACT CCC } \\
\text { ACT CCT }\end{array}$ & $\begin{array}{c}\text { GTC AGC GGA CTC } \\
\text { TGG ATT }\end{array}$ \\
\hline
\end{tabular}




\section{Statistical Analysis}

For comparison of CD73 protein expression with or without electroporation and for comparison of RNA expression of lineage markers with or without electroporation, a normal distribution was assumed and one-way analyses of variance (ANOVA) and Student $t$-test for unpaired samples were used. Data were analyzed with JMP 5.0.1 for Windows (SAS Institute, Inc., Carey, NC). A 99\% $(P<0.01)$ confidence interval was applied for statistical significance.

\section{RESULTS}

\section{Efficient Electroporation of MSCs}

A leading electroporation system, the Invitrogen Neon ${ }^{\mathrm{TM}}$ Transfection System, was used to optimize transfection efficiency and viability of MSCs. According to the manufacturer's instructions, the pulse magnitude was varied from $900-1700 \mathrm{~V}$ and the pulse duration and frequency were held constant at $20 \mathrm{~ms}$ and 1 per transfection, respectively. Transfection efficiency of MSCs generally increased with increasing voltage, reaching a maximum transfection efficiency of approximately $55 \%$ at $1600 \mathrm{~V}$. However, increasing voltage also induced greater cell death. At voltage pulses greater than $1500 \mathrm{~V}$, cell viability plummeted to $20 \%$ or lower (Fig. 1). Low cell survival may be tolerable or even desirable for some research studies, but in most cases viability is as essential as transfection efficiency. Thus, here we define the transfection "score" as the (Viability *

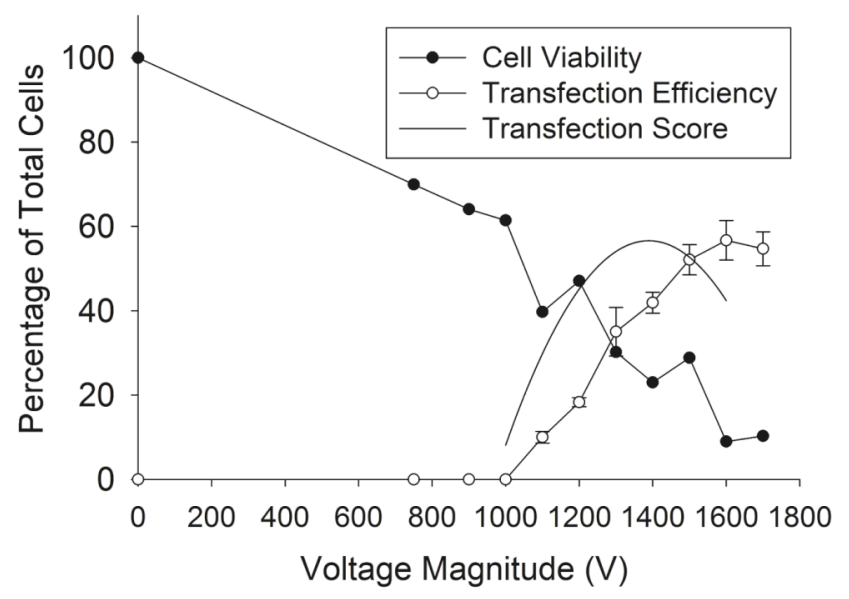

Fig. (1). Optimization of MSC Transfection. MSCs were electroporated with a single, $20 \mathrm{~ms}$ pulse over a range of pulse magnitudes using a plasmid encoding GFP. Viability, trans-fection efficiency and transfection score $v s$. pulse magnitude. Cell viability was defined as a percentage of electroporated cells per well relative to the total number of cells per well in control wells and the relative percentage was plotted as a function of pulse magnitude. Transfection efficiency was defined as the number of GFP positive cells relative to the total number of cells in the well and the relative percentage was plotted as a function of pulse magnitude. A transfection score was defined as a function of both cell viability and transfection efficiency (see Materials and Methods) and was plotted as a function of pulse magnitude. The transfection score was maximized at a pulse magnitude of $1400 \mathrm{~V}$ and thus was identified as the optimum condition for MSC transfection.
Efficiency)/20. The highest transfection score occurred at a pulse magnitude of $1400 \mathrm{~V}$ (with a frequency of 1 and a pulse duration of $20 \mathrm{~ms}$; Fig. 1).

\section{Transfected MSCs Retain Expression of Multipotent Marker, CD73}

The ability of MSCs to retain multipotency after electroporation is essential for subsequent study of cell behavior. CD73 is a known marker of MSC multipotency [19] and so expression of CD73 was tracked using immunofluorescence for three passages following electroporation. Cells were electroporated at $1000 \mathrm{~V}$ and $1500 \mathrm{~V}$ with a frequency of 1 per transfection and a pulse duration of $20 \mathrm{~ms}$. These parameters were chosen to flank the optimum transfection condition ( $1400 \mathrm{~V}, 20 \mathrm{~ms}, 1$ pulse). Electroporation was conducted at passage 7 and CD73 expression was determined at passages 9 - 12. Large numbers of cells maintained CD73 expression after electroporation with both $1000 \mathrm{~V}(99.7 \% \pm$ $1.0 \%)$ and $1500 \mathrm{~V}(99.7 \% \pm 0.4 \%)$ and did not differ from unmanipulated cells $(99.9 \% \pm 0.3 \% ; \mathrm{n}>4$ fields from 3 different wells from 3 different experiments for each condition; $P=0.84$, control vs. $1000 \mathrm{~V} ; P=0.39$, control vs. 1500 V; Fig. 2). Thus CD73 expression is maintained following electroporation at a pulse magnitude of up to $1500 \mathrm{~V}$ with a $20 \mathrm{~ms}$ pulse duration.

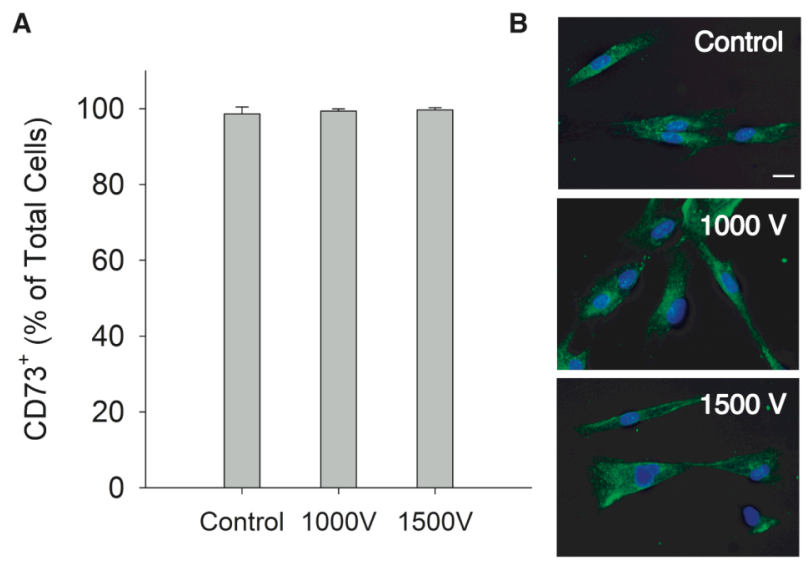

Fig. (2). MSCs Maintain a Multipotent Phenotype. MSCs were electroporated with a single $20 \mathrm{~ms}$ pulse at $1000 \mathrm{~V}$ or $1500 \mathrm{~V}$. CD73 protein expression was evaluated using immunofluorescence and the number of positive cells was determined in multiple fields $(n>4)$ from 3 different experiments and expressed as a percentage of total cells viewed. The percentage of cells expressing CD73 protein soon after electroporation was compared to that of unmanipulated MSCs. CD73 expression was tracked for three passages and cumulative results were reported. A) Comparison of CD73 protein expression in electroporated MSCs compared to unmanipulated controls. CD73 expression did not vary between electroporated and control MSCs $(P=0.84$, control vs. $1000 \mathrm{~V} ; P=$ 0.39 , control vs. $1500 \mathrm{~V})$. B) Representative photomicrographs showing CD73 expression (green) in electroporated MSCs compared to controls. Scale bar $=10 \mu \mathrm{m}$.

\section{Transfected MSCs do not Express Mature Cell Markers of Bone, Muscle and Fat}

The kinetics of the loss of CD73 with differentiation is not well understood and so it is possible that while nearly all MSCs express CD73 following electroporation, some may 
have begun to differentiate. To test this possibility, we probed the RNA of MSCs one passage after electroporation at $1000 \mathrm{~V}$ and $1500 \mathrm{~V}$ (20 ms, 1 pulse) with primers for mature cell markers of osteoblasts (osteopontin and osteocalcin), adipocytes (PPAR $\gamma-2)$ and cardiomyocytes (cardiac troponin-T) using RT-PCR. Expression of either osteocalcin or cardiac troponin- $T$ was not detected in the control or experimental populations. Low levels of osteopontin and PPAR $\gamma$-2 RNA expression were detected in both control and electroporated H1MSC populations. However, expression levels did not vary significantly between control populations and those exposed to electroporation $(P=0.98$, control vs. $1000 \mathrm{~V}$, osteopontin; $P=0.70$, control vs. $1500 \mathrm{~V}$, osteopontin; $P=0.04$, control vs. $1000 \mathrm{~V}$, PPAR $\gamma-2 ; P=0.20$, control vs. $1500 \mathrm{~V}$, PPAR $\gamma-2$; Table 2). Thus, electroporation at levels sufficient for gene transfection does not rapidly induce expression of markers corresponding to mature or developing osteoblasts, adipocytes or cardiomyocytes.

Table 2. Expression of Tissue Linage Markers of hESCderived MSCs Normalized to $\beta$-Actin

\begin{tabular}{|c|c|c|c|}
\hline Lineage Marker & Control & $\mathbf{1 0 0 0}$ Volts & $\mathbf{1 5 0 0}$ Volts \\
\hline \hline Osteocalcin & 0 & 0 & 0 \\
\hline Osteopontin & $0.23 \pm 0.02$ & $0.26 \pm 0.02$ & $0.26 \pm 0.02$ \\
\hline Cardiac Troponin-T & 0 & 0 & 0 \\
\hline PPAR $\gamma-2$ & $0.20 \pm 0.02$ & $0.28 \pm 0.02$ & $0.25 \pm 0.02$ \\
\hline
\end{tabular}

\section{DISCUSSION}

Electroporation is often used to genetically modify stem cells, which are notoriously difficult to transfect [20-29]. This study was conducted to evaluate possible negative effects of electroporation on hESC-derived MSCs, namely the loss of potency and the induction of unanticipated differentiation. Here we show that under conditions conductive to MSC transfection, electroporation did not rapidly alter potency or induce differentiation of MSCs.

There are several parameters to be evaluated when identifying optimum transfection conditions with electroporation including, pulse magnitude, pulse duration, pulse frequency, plasmid concentration, and cell concentration. In addition, one must consider the cell type, the desired outcome (i.e., relative importance of transfection efficiency and viability) and electroporation system to be used. Thus the number of potential permutations is large and evaluating every permutation is not practically feasible. To narrow the scope, we identified the pulse magnitude as the most crucial parameter as minor variations in pulse magnitude can dramatically impact cell morphology, granularity and survival. Our approach was to identify the optimum parameters for transfection of MSCs and to test variations in pulse magnitude $(1000 \mathrm{~V}$ and $1500 \mathrm{~V})$ flanking that of the optimum condition $(1400 \mathrm{~V})$. We found that CD73 protein expression is maintained following electroporation which suggests the multipotency of MSCs, or at least a substantial fraction of
MSCs, is maintained. This result is consistent with previous reports by Colleoni et al. and Ferreira et al. which showed MSCs are able to differentiate into adipogenic, chrondogenic, and osteogenic lineages following electroporation [5, 11]. Still, karyotypic analysis should be considered, especially if genetically altered cells are to be used clinically.

Even if most cells of a population express markers of MSCs and can give rise to cells of multiple lineages, we cannot be certain whether or not a fraction of the cells have begun or completed differentiation. This is possible, since the loss of multipotency markers and the emergence of proteins of mature cells can be overlapping. The possibility of inducing differentiation with electroporation was evaluated using RT-PCR with subsequent densitometry analysis of bands corresponding to osteopontin, osteocalcin, PPAR $\gamma-2$ and cardiac troponin-T expression. Expression was evaluated one passage after electroporation and results suggest that electroporation, under conditions conducive to MSC transfection, does not induce near-term differentiation of MSCs. We selected early and late markers of osteoblast differentiation (osteopontin and osteocalcin, respectively) in case incomplete differentiation was triggered or differentiation had proceeded to completion at the time of study. It should be noted that the number of proteins probed is certainly not exhaustive and so differentiation of other cell types may have occurred, or differentiation may not have occurred to the extent needed to detect a particular protein of interest. In addition, it should be noted that the stem cell population studied here were human in species, mesenchymal in nature and embryonic stem cell in source. It is possible that mesenchymal stem cells from other sources (e.g., bone marrow, adipose tissue) and species (e.g., mouse, rat) may exhibit varied responses to electroporation, especially responses related to cell state.

\section{CONCLUSION}

We have shown that electroporation can efficiently transfect embryonic stem cell-derived MSCs. The optimum transfection conditions were a single pulse at a pulse magnitude of $1400 \mathrm{~V}$ and a duration of $20 \mathrm{~ms}$. The resultant transfection efficiency was approximately $42 \%$ with a $25 \%$ viable fraction. At pulse magnitudes flanking $1400 \mathrm{~V}$, electroporation does not rapidly affect MSC potency or induce differentiation. Thus electroporation of MSCs is an effective method of gene transfer that can be used to augment the study of stem cell behavior and ultimately advance clinical application of stem cells.

\section{ACKNOWLEDGEMENTS}

The authors would like to thank Peiman Hematti, University of Wisconsin-Madison, for providing H1-derived MSCs and Nicholas Kouris of the Ogle laboratory for technical assistance.

Supported by funding from the National Institutes of Health (HL089679).

\section{CONFLICT OF INTEREST}

None Declared. 


\section{REFERENCES}

[1] Aggarwal S, Pittenger MF. Human mesenchymal stem cells modulate allogeneic immune cell responses. Blood 2005; 105(4): 1815.

[2] Pittenger MF, Mackay AM, Beck SC, et al. Multilineage potential of adult human mesenchymal stem cells. Science 1999; 284(5411): 143.

[3] Uccelli A, Pistoia V, Moretta L. Mesenchymal stem cells: a new strategy for immunosuppression? Trends Immunol 2007; 28(5): 219-26.

[4] Helledie T, Nurcombe V, Cool SM. A simple and reliable electroporation method for human bone marrow mesenchymal stem cells. Stem Cells Dev 2008; 17(4): 837-48.

[5] Colleoni S, Donofrio G, Lagutina I, Duchi R, Galli C, Lazzari G. Establishment, differentiation, electroporation, viral transduction, and nuclear transfer of bovine and porcine mesenchymal stem cells. Cloning Stem Cells 2005; 7(3): 154-66.

[6] Chang DC, Chassy BM, Saunders JA, Sowers AE. Guide to electroporation and electrofusio. USA: Academic Press San Diego 1992.

[7] Neumann E, Sowers AE, Jordan CA. Electroporation and electrofusion in cell biology. USA: Springer Us 1989.

[8] Andre F, Mir L. DNA electrotransfer: its principles and an updated review of its therapeutic applications. Gene Ther 2004; 11: S33S42.

[9] Chen C, Smye S, Robinson M, Evans J. Membrane electroporation theories: a review. MBEC 2006; 44(1): 5-14.

[10] Tsong TY. Electroporation of cell membranes. Biophys J 1991; 60(2): 297-306.

[11] Ferreira E, Potier E, Logeart-Avramoglou D, SalomskaiteDavalgiene S, Mir L, Petite H. Optimization of a gene electrotransfer method for mesenchymal stem cell transfection. Gene Ther 2008; 15(7): 537-44.

[12] Hamm A, Krott N, Breibach I, Blindt R, Bosserhoff AK. Efficient transfection method for primary cells. Tissue Eng 2002; 8(2): 23545.

[13] Titushkin IA, Cho MR, Eds. Controlling cellular biomechanics of human mesenchymal stem cells. IEEE 2009.

[14] Sun S, Liu Y, Lipsky S, Cho M. Physical manipulation of calcium oscillations facilitates osteodifferentiation of human mesenchymal stem cells. FASEB J 2007; 21(7): 1472.

[15] Sauer H, Rahimi G, Hescheler J, Wartenberg M. Effects of electrical fields on cardiomyocyte differentiation of embryonic stem cells. J Cell Biochem 1999; 75(4): 710-23.
[16] Trivedi P, Hematti P. Derivation and immunological characterization of mesenchymal stromal cells from human embryonic stem cells. Exp Hematol 2008; 36(3): 350-9.

[17] Misawa K, Nosaka T, Morita S, et al. A method to identify cDNAs based on localization of green fluorescent protein fusion products. Proc Natl Acad Sci USA 2000; 97(7): 3062-6.

[18] Ogle BM, Butters KA, Plummer TB, et al. Spontaneous fusion of cells between species yields transdifferentiation and retroviral transfer in vivo. FASEB J 2004; 18(3): 548-50.

[19] Dominici M, Le Blanc K, Mueller I, et al. Minimal criteria for defining multipotent mesenchymal stromal cells: the international society for cellular therapy position statement. Cytotherapy 2006; 8(4): 315-7.

[20] Kim HJ, Im GI. Electroporation-mediated transfer of SOX Trio Genes (SOX-5, SOX-6, SOX-9) to enhance the chondrogenesis of mesenchymal stem cells. Stem Cell Dev 2011.

[21] Im GI, Kim HJ. Electroporation-mediated gene transfer of SOX trio to enhance chondrogenesis in adipose stem cells. Osteoarth Cartilage 2011; 19(4): 449-57.

[22] Lee JS, Lee JM, Im GI. Electroporation-mediated transfer of Runx2 and Osterix genes to enhance osteogenesis of adipose stem cells. Biomaterials 2011; 32(3): 760-8.

[23] Ziv R, Steinhardt Y, Pelled G, Gazit D, Rubinsky B. Microelectroporation of mesenchymal stem cells with alternating electrical current pulses. Biomed Microdevices 2009; 11(1): 95101.

[24] Helledie T, Nurcombe V, Cool SM. A simple and reliable electroporation method for human bone marrow mesenchymal stem cells. Stem Cell Dev 2008; 17(4): 837-48.

[25] Valero A, Post JN, van Nieuwkasteele JW, Ter Braak PM, Kruijer $\mathrm{W}$, van den Berg A. Gene transfer and protein dynamics in stem cells using single cell electroporation in a microfluidic device. Lab Chip 2008; 8(1): 62-7.

[26] Costa M, Dottori M, Sourris K, et al. A method for genetic modification of human embryonic stem cells using electroporation. Nat Protoc 2007; 2(4): 792-6.

[27] Tompers DM, Labosky PA. Electroporation of murine embryonic stem cells: a step-by-step guide. Stem Cell 2004; 22(3): 243-9.

[28] Furuya M, Yasuchika K, Mizutani K, Yoshimura Y, Nakatsuji N, Suemori H. Electroporation of cynomolgus monkey embryonic stem cells. Genesis 2003; 37(4): 180-7.

[29] Weissinger F, Reimer P, Waessa T, et al. Gene transfer in purified human hematopoietic peripheral-blood stem cells by means of electroporation without prestimulation. J Lab Clin Med 2003; 141(2): 138-49.

This is an open access article licensed under the terms of the Creative Commons Attribution Non-Commercial License (http://creativecommons.org/licenses/by$\mathrm{nc} / 3.0 /$ ), which permits unrestricted, non-commercial use, distribution and reproduction in any medium, provided the work is properly cited. 